\title{
The early 1950s regime shift in temperature in Taiwan and East Asia
}

\author{
Tzu-Ting Lo $\cdot$ Huang-Hsiung Hsu
}

Received: 14 November 2006/Accepted: 17 August 2007/Published online: 26 September 2007

(C) Springer-Verlag 2007

\begin{abstract}
A summer climate regime shift in temperature in Taiwan and East Asia during the early 1950s was identified in this study. The event was characterized by a cooling land-warming ocean dipole in East Asia and the western North Pacific, marking the decreasing land-sea thermal contrast from the 1940s to the 1950s. The corresponding sea surface temperature (SST) anomaly was characterized by the sign flipping of a north-south dipole in the western North Pacific from north/cool-south/warm to north/warm-south/cool, indicating a weakening northsouth SST gradient in the area. The corresponding change in mean sea level pressure was characterized by the rising pressure in continental East Asia and the Philippine Sea, and the falling pressure over the extratropical western North Pacific to the east of Japan. This change was the reflection of a weakening thermal low in the continental East Asia, a weakening monsoon trough in the tropical western North Pacific, a strengthening and southwestwardexpanding ridge in the subtropical western North Pacific, and a deepening mid-latitude trough over eastern China and Japan. The phase reversal of the SST anomaly in the western North Pacific exhibited the characteristics of the Pacific Decadal Oscillation (PDO), but lagged behind the phase reversal of the PDO in the extratropical North Pacific by several years. The connection with the PDO is speculated, although the mechanism is not understood.
\end{abstract}

This paper is a contribution to the AMIP-CMIP Diagnostic Sub-project on General Circulation Model Simulation of the East Asian Climate, coordinated by W.-C. Wang.

T.-T. Lo $\cdot$ H.-H. Hsu $(\bowtie)$

Department of Atmospheric Sciences,

National Taiwan University, Taipei, Taiwan

e-mail: hsu@atmos1.as.ntu.edu.tw

\section{Introduction}

Climate regime shifts in East Asia and the Pacific have been observed and documented in many studies. These shifts are often characterized by transition (and abrupt change in some events) between climate states. Among several climate regime shifts since 1900, the 1976-1977 event is probably one of the most well documented phenomena. Changes in sea surface temperature (SST), precipitation, and circulation in many regions (including East Asia), and the characteristics of El Niño/Southern Oscillation were observed during this event (e.g., Nitta and Yamada 1989; Trenberth 1990; Tanimoto et al. 1993; Miller et al. 1994; Trenberth and Hurrell 1994; Mantua et al. 1997; An and Wang 2000; Seager et al. 2001; Wu and Wang 2002; Gong and Ho 2002; Ju et al. 2005; Chang et al. 2000b; Hung et al. 2004). Other climate regime shifts were also detected in the North Pacific and East Asia. For example, Yasunaka and Hanawa (2002) applied the empirical orthogonal function analysis to the SST in the Northern Hemisphere and identified regime shifts at 1925/ 26, 1945/46, 1957/58, 1970/71, 1976/77, and 1988/1989. Yonetani (1992) reported discontinuous climate changes in Japan in 1914, 1949, 1957, 1967 after 1900.

Climate regime shifts in East Asia were often found associated with the large-scale decadal-interdecadal oscillation, such as the Pacific Decadal Oscillation (PDO), which is characterized by the oscillation of the sea surface temperature anomaly (SSTA) in the extratropical North Pacific (e.g., Mantua et al. 1997; Zhang et al. 1997). The PDO exhibits a spatial pattern similar to the El Niño/La Niña in the equatorial and North Pacific, but oscillates in the decadal-interdecadal time scales, with larger amplitude in the extratropics than in the tropics. Some of those events identified by Yasunaka and Hanawa (2002) coincided with 
the reversal of the PDO, namely 1925, 1947, 1977, and 1989 (Mantua et al. 1997; Hare and Mantua 2000). Precipitation changing from below normal to above normal around 1978 was observed in central China, southern part of northeastern China, and the Korean peninsula ( $\mathrm{Ju}$ et al. 2005; Ho et al. 2003). This event again coincided with the reversal of the PDO. Spring rainfall in Taiwan was also found affected by the PDO (Hung et al. 2004).

Watanabe and Nitta (1999) documented the abrupt warming in northern East Asia in the late 1980s, which was associated with the snow cover decrease in the Eurasian continent after 1987. Similarly, Tachibana et al. (1996) reported the abrupt decrease of sea ice over the Okhotsk Sea in the same period. These climate regime shifts coincided with the reversal of the Arctic Oscillation in the late 1980s (Rodionov and Overland 2005). On the other hand, Hare and Mantua (2000) also identified a regime shift in the PDO around 1989. These studies suggested the possible linkage between the East Asian climate regime shifts and the large-scale decadal-interdecadal oscillations, although the mechanisms may not be clear.

During our study on the long-term climate variation in Taiwan, an abrupt increase in summer temperature occurring in the early 1950 s was identified. As will be shown later, this phenomenon was not a local feature; instead, it was influenced by a regime shift in the large-scale circulation and the land/SST in East Asia and the western North Pacific. To the best of our knowledge, this event has not been well documented in the previous studies and is poorly understood. In this study, we explored the characteristics of this regime shift and its possible linkage with the PDO. The results presented here may shed light and enhance our understanding on the nature of the climate regime shift and the interdecadal climate variability in East Asia and the western North Pacific. Data and methodology are described in Sect. 2. The characteristics of temperature and mean sea level pressure (MSLP) fields are reported in Sect. 3. Section 4 discusses the temporal evolution of the corresponding spatial pattern from 1940s to 1950s. Conclusions and discussion are presented in Sect. 5.

\section{Data and methodology}

Main data used in this study include (1) the Met OfficeGlobal Sea Ice Coverage and Sea Surface Temperature (HadISST 1.1 , monthly, $1^{\circ}$ by $1^{\circ}$, 1870-present; Rayner et al. 2003), (2) the Hadley Centre's historical MSLP (HADSLP2, monthly, $5^{\circ}$ by $5^{\circ}$, 1850-present; Allan and Ansell 2006), (3) the Climate Research Unit (CRU) temperature and precipitation (TS2.0, monthly, $0.5^{\circ}$ by $0.5^{\circ}$, 1901-2002; Mitchell et al. 2004), and (4) the monthly temperature at seven long-term stations in Taiwan (1911-
2002). Averaged temperature at the seven stations, which are evenly distributed in Taiwan, was computed to represent the island-wide mean temperature. The following procedure was applied to the data to retain only the decadal-interdecadal fluctuations. A nine-point Gaussian lowpass filter was applied to the data to remove the interannual variability. Linear trend, defined as the linear regression of a time series, was further subtracted from the filtered data at each grid point to remove the secular variation.

Because the regime shift discussed here occurred in the early 1950s when the actual observations were not as abundant as in the later years, four more long-term data sets were analyzed and compared to check the reliability of the results presented here. These data sets are: (1) the Kaplan extended SST V2 (monthly, $5^{\circ}$ by $5^{\circ}$, 1856-present; Kaplan et al. 1998), (2) the NOAA merged air and SST (monthly, $5^{\circ}$ by $5^{\circ}$, 1880-present; Smith et al. 2005), (3) the GISS surface temperature analysis (monthly, $1^{\circ}$ by $1^{\circ}$, 1880-present; Hansen et al. 1999), and (4) the Met Office-Global Mean Sea-Level Pressure (GMSLP, monthly, $5^{\circ}$ by $5^{\circ}$, 1871-1998; Basnett and Parker 1997). As will be shown, the analysis based on these different data sets yields essentially same results.

The sequential algorithm designed by Rodionov (2004) was used in this study to identify climate regime shifts in time series. The method is based on the technique for identifying the significant change in the sequential running means of certain period. A screening procedure was proposed in Rodionov (2004) to compute a regime shift index (hereafter RSI). A positive RSI indicates the identification of a regime shift. A larger RSI yields more confidence on the identification. Readers are referred to Rodionov (2004) for the details of the algorithm. In this study, the RSI was computed based on 15-year running means. This procedure implicitly chooses the 15 -year mean as a climate state and the regime shift is basically referred to the change between the climate states of interdecadal time scale. The 0.1 significance level was adopted in the procedure of identifying climate regime shifts. While a positive RSI means the identification of a regime shift, the Rodionov method does not provide a test procedure to show the significance of the identified shift. To check the reliability of the early $1950 \mathrm{~s}$ regime shift, a simple moving $t$-test method (Gullett et al. 1990; Ducre-Robitaille et al. 2003) and the Mann-Whitney-Pittitt method (Pittitt 1979; Kiely 1999) were also applied.

A meaningful climate regime shift should occur in a large region, instead of at just few isolated locations. The following regional analysis, similar to the Lepage test suggested by Yonetani (1992) and Yasunaka and Hanawa (2002), was performed to identify the climate regime shift in East Asia. The RSI in a specific year was computed at every grid point within $\left(90^{\circ} \mathrm{E}-140^{\circ} \mathrm{E}, 20^{\circ} \mathrm{N}-50^{\circ} \mathrm{N}\right)$. 
Number of points with positive RSI (NRSI) in the region was counted for a 5-year period, and assigned to the year in the center of the 5-year period. For example, 1951 was assigned to the 1949-1953 period. A NRSI time series was then constructed for every 5-year period in a running manner from 1921 to 1990 . The timing of regime shift for the region as a whole was defined as the year, when the normalized NRSI exceeds one positive standard deviation. The normalized NRSI tends to be continuously positive or negative for several years near the climate regime shift, because of the use of running means for the regime shift identification and the way computing NRSI. The year with the largest NRSI in a period of continuously positive value was marked as the year of climate regime shift for the region.

To be sure that the NRSI does represent a global significance, a Monte Carlo approach was adopted to estimate the number of points (i.e., NRSI), where the early 1950s regime shift is identified, can be obtained from randomly scrambled time series. Each temperature time series in the chosen region was randomly scrambled a thousand times. The NRSI in the early1950s was computed for each scramble to produce 1,000 values. The 50th largest NRSI is 55. If the actual NRSI is larger than 55, it means that the global significance is achieved at the 0.05 level.

\section{Characteristics of regime shift}

In the study of climate variation in Taiwan, we encountered a dramatic warming occurring in the early 1950s. This feature is clearly seen in Fig. 1, which shows the time series of 3-month running mean temperature in Taiwan from February to November during 1915-2000. Nine-point Gaussian running means are presented to show the decadalinterdecadal fluctuation. The abrupt warming is noted to occur mainly in the spring and summer (from MAM to JJA) by a comparison between the time series shown in the upper and middle panels of Fig. 1. The summer (JuneAugust, JJA) temperature increased by more than $0.5^{\circ} \mathrm{C}$ from 1949 to 1954. The abrupt warming in the 1950s is superimposed upon a long-term warming trend, which started in the beginning of the twentieth century and continues to the present. An abrupt shift is not evident in the autumn and winter temperature, while the long-term warming trend is clearly the major characteristic, as seen in the middle panel of Fig. 1.

Such a dramatic change was at first surprising to us and an instrument change was suspected responsible for this dramatic change. However, the instrument maintenance record kept by the Central Weather Bureau in Taiwan indicates no change in the instrument and observation methodology between the late 1940s and the early 1950s. If

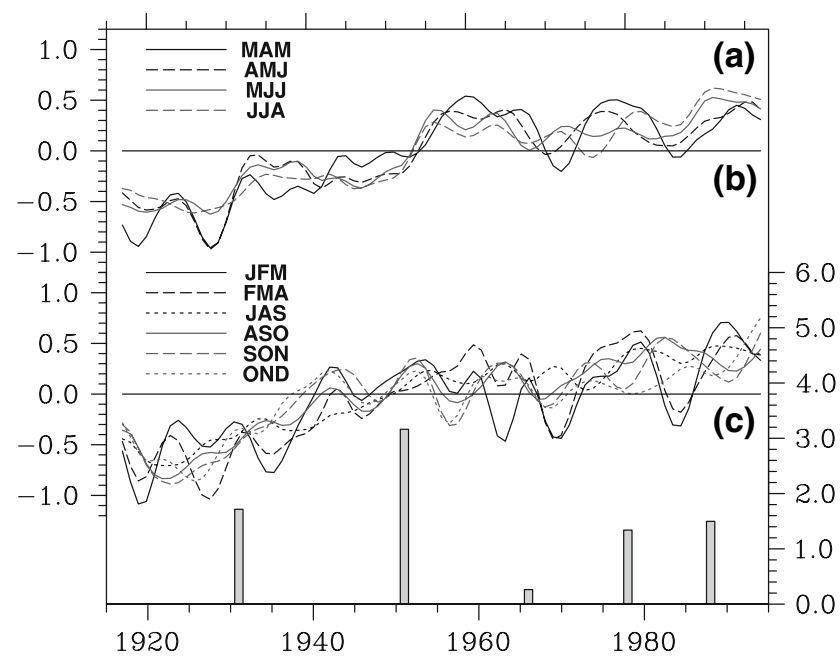

Fig. 1 Time series of 9-year Gaussian running mean Taiwan temperature: (upper panel) March-May (MAM), April-June (AMJ), May-July $(M J J)$, and June-August (JJA), and (middle panel) January-March $(J F M)$, February-April (FMA), July-September $(J A S)$, August-October $(A S O)$, September-November $(S O N)$, and October-December $(O N D)$. RSI for the JJA time series is shown in (lower panel) to indicate the detection of regime shift

it were caused by the instrument change, the dramatic change should also be present in the autumn and winter temperature time series. Lack of this abrupt change in the autumn and winter is another piece of supporting evidence which rules out the possibility of instrument change. Based on these two pieces of evidence, the observed abrupt warming in Taiwan is believed to be a real climate signal. The RSI for the JJA temperature, shown in the lower panel of Fig. 1, indicates the occurrences of climate regime shift in 1931, 1951, 1966, 1978, and 1988. The 1951 shift, as indicated by the largest RSI, is the most significant one among the five events and coincides with the abrupt temperature increase described above.

Further studies on the corresponding temperature distribution indicate the simultaneous occurrence of abrupt temperature changes in a much larger region surrounding Taiwan. Figure 2a presents the area-mean JJA temperature in two nearby regions, namely China in $\left(100^{\circ} \mathrm{E}-120^{\circ} \mathrm{E}\right.$, $30^{\circ} \mathrm{N}-50^{\circ} \mathrm{N}$; CRU temperature) and the subtropical western North Pacific in $\left(140^{\circ} \mathrm{E}-160^{\circ} \mathrm{E}, 2^{\circ} \mathrm{N}-30^{\circ} \mathrm{N}\right.$; HadISST), along with the Taiwan temperature. To remove the interannual fluctuation, the nine-point Gaussian running-mean temperatures are presented in Fig. 2. The China temperature dropped significantly and continuously between 1947 and 1955 by about $1^{\circ} \mathrm{C}$, while the Pacific temperature increased by about $0.2^{\circ} \mathrm{C}$ around 1950 . The smaller increase in the latter is reasonable, because it is SST while the former is land surface temperature. Regime shifts around 1950 were also detected in these two time series (RSI not shown). The abrupt warming in Taiwan appeared 
to occur concurrently with the warming in the subtropical western North Pacific and the cooling in the continental East Asia. While the Taiwan temperature exhibits clear warming trend, both the China and Pacific temperature exhibit stronger oscillatory signals and weaker linear trend. To evaluate the influence of long-term trends, a linear regression analysis was applied to the three time series to define the linear trends, which were then subtracted from the corresponding time series. The abrupt temperature changes in the three detrended time series are still evident as seen in Fig. 2b. This result confirms the existence of the abrupt temperature change, which was not an artifact due to the linear warming trend. Despite of this, linear trends in all variables were removed in the following analysis to minimize the possible effect of the long-term trend in certain regions. Since the temperature change was most dramatic in the summer, the following analysis will focus on the JJA season.

To demonstrate the spatial pattern of this abrupt temperature change in East Asia and the western North Pacific, the 15-year mean JJA temperature in 1936-1950 was subtracted from the 15-year mean JJA temperature in
1951-1965. The 15-year period was chosen to ensure the length of averaging period is much longer than the regime shift. The temperature change pattern shown in Fig. $3 \mathrm{a}$ is characterized by a cooling land-warming ocean dipole. The cooling is observed in most part of China and Siberia, while the warming is observed in the southeastern coast of China, Taiwan, and the western North Pacific between $10^{\circ} \mathrm{N}$ and $50^{\circ} \mathrm{N}$. The China and Pacific temperature time series shown in Fig. 2 represent the most significant cooling and warming regions, respectively. This result indicates that the abrupt summer temperature change did not occur only in Taiwan. Instead, it was a phenomenon occurred in a large part of East Asia and the subtropical western North Pacific.

One may suspect the reliability of the observed changes shown in Fig. 3, because of the less abundant and spottier observation in the early years. Similar results obtained from other data sets (i.e., NOAA and GISS surface temperature, and Kaplan SST) are shown in Fig. 4 for comparison. During this computation, the temperature change was calculated only at the points where the number of missing data is $<15 \%$ in each 15 -summer period. Left
Fig. 2 Time series of 9-year Gaussian running-mean temperature in Taiwan, China $\left(100^{\circ} \mathrm{E}-120^{\circ} \mathrm{E}, 30^{\circ} \mathrm{N}-50^{\circ} \mathrm{N}\right)$, and the western North Pacific $\left(140^{\circ} \mathrm{E}-160^{\circ} \mathrm{E}, 25^{\circ} \mathrm{N}-30^{\circ} \mathrm{N}\right)$ : $\mathbf{a}$ undetrended and $\mathbf{b}$ detrended
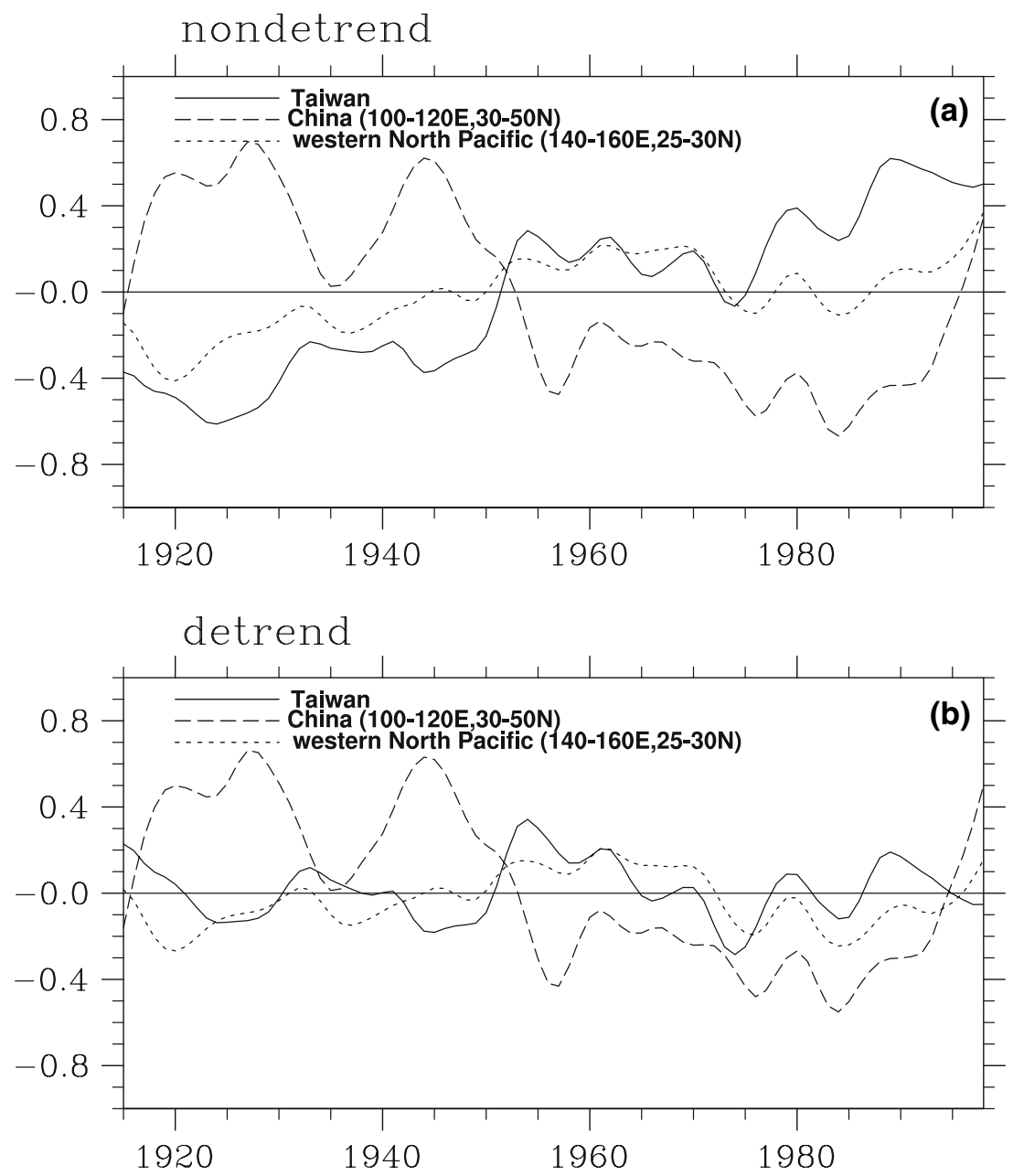
Fig. 3 Differences between two 15-year periods: namely, 1951-1965 and 1935-1950: $\mathbf{a}$ temperature and $\mathbf{b}$ precipitation. Contour intervals are $0.2^{\circ} \mathrm{C}$ and $10 \mathrm{~mm}$ for temperature and precipitation, respectively. Solid and dashed lines denote positive and negative values, respectively. Values that are statistically significant at the 0.1 level are shaded (a) SST/SAT

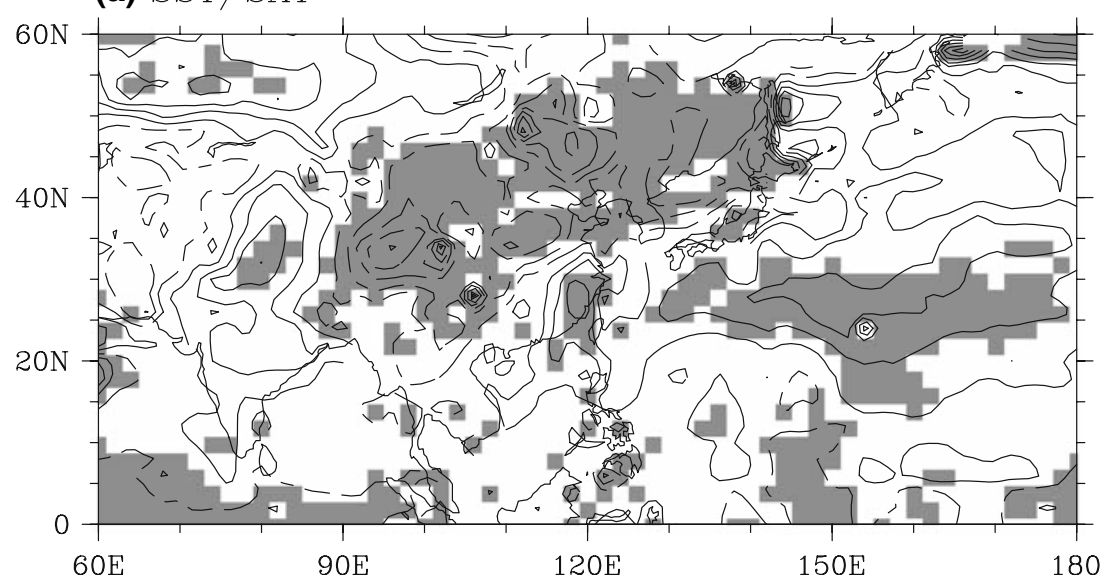

(b) Precipitation

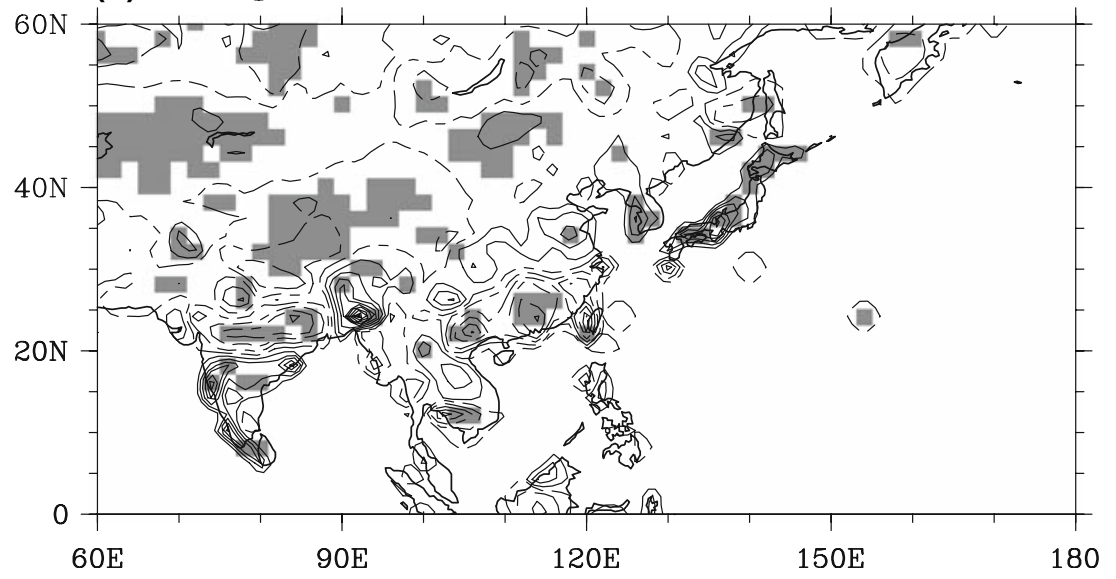

panel of Fig. 4 shows the change patterns in the detrended temperature derived from the CRU/HadISST, NOAA surface temperature, and Kaplan SST data sets. The GISS surface temperature is not used, because the missing data in the earlier years make it difficult to identify the trend at many inland points. The consistency between the three is clearly evident. The right panel of Fig. 4 presents the change pattern in the original (i.e., non-detrended) temperature field. The similarity between the three is again evident. Although the GISS temperature data have more missing data in the inner continent, the negative temperature change near the eastern coast of the Asian continent, where observations were more abundant, still exists. These results derived from different analyses confirm the existence of the land cooling-ocean warming pattern between the two 15-year periods before and after 1951 .

The corresponding precipitation difference, shown in Fig. 3b, exhibits negative anomaly in southern China and Taiwan, and positive anomaly in northern China, Korea, and Japan. This indicates a pattern exhibiting two contrasting climate conditions: warming/drying in the southern part of East Asia, and cooling/wetting in the northern part of East Asia. It is interesting to note that this pattern resembles the tripole precipitation pattern that dominates both the interannual and interdecadal variability of the East Asian summer precipitation (e.g., Weng et al. 1999; Hsu and Lin 2007). Although the precipitation indicates a signal of regime shift in certain regions, a calculation of NRSI does not indicate the regime shift in precipitation occurred in East Asia as a whole. It is not clear in the present study why the regime shift in precipitation in East Asia is not as robust as in temperature. On the other hand, the temperature and precipitation are not always connected in a systematic way, considering that precipitation is a much more random variable in both time and space than temperature. Since the regime shift occurred mainly in the temperature field, the rest of discussion will focus on the temperature-related features.

The corresponding MSLP difference is shown in Fig. 5a to reveal the corresponding circulation change. The change pattern is characterized by: (a) the positive anomaly in the continental Asia (except near the coast) roughly between $30^{\circ} \mathrm{N}$ and $50^{\circ} \mathrm{N}$, the Philippine Sea and South Asia, and the western North Pacific north of $50^{\circ} \mathrm{N}$, and (b) the negative 
(a) CRU+HadISST-detrend

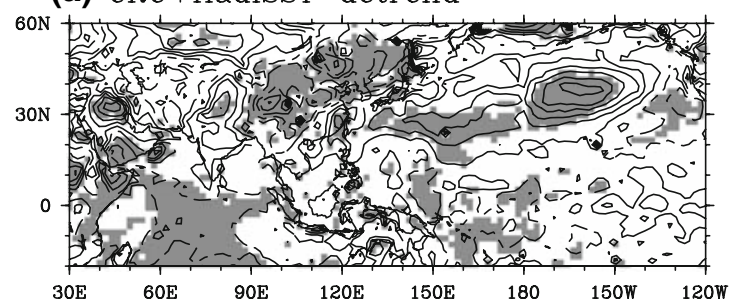

(c) NOAA-detrend

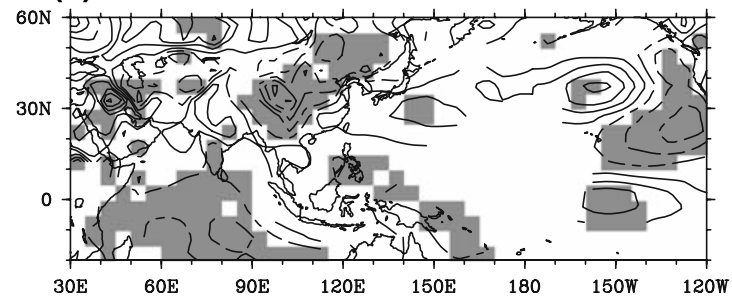

(e) Kaplan-detrend

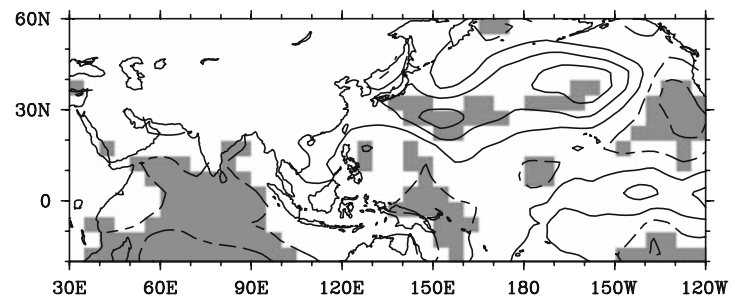

(b) CRU+HadISST-original

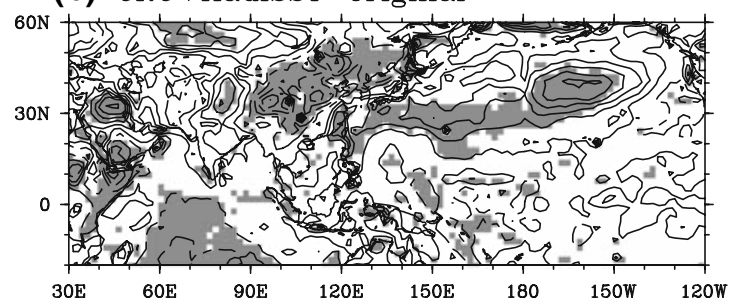

(d) NOAA-original

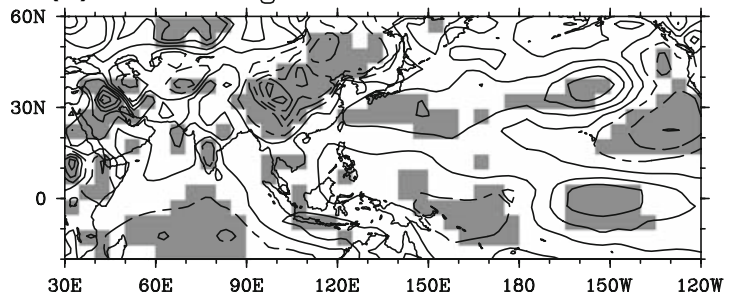

(f) GISS-original

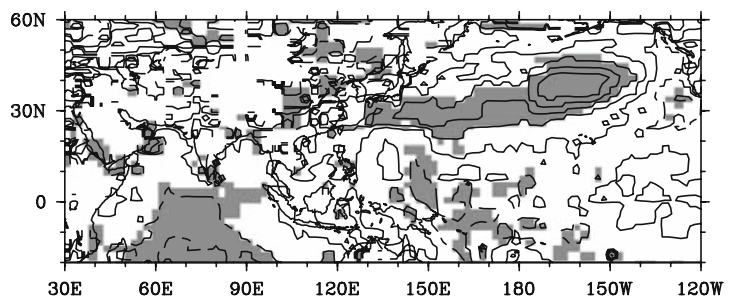

Fig. 4 Same as in Fig. 3a, except for the detrended a CRU + HadISST, c NOAA surface temperature, and e the Kaplan SST, and the nondetrended $\mathbf{b}$ CRU + HadISST, $\mathbf{d}$ NOAA surface temperature, and $\mathbf{f}$ GISS surface temperature in a larger domain

anomaly over central eastern China, Japan and the western North Pacific between $30^{\circ} \mathrm{N}$ and $50^{\circ} \mathrm{N}$. The pattern exhibits a three-layer meridional structure in both continental Asia and the western North Pacific. Note the similarity of the latter one to the Pacific-Japan pattern (Nitta 1987), which is a dominant summer teleconnection pattern in the region.

To understand the meaning of these changes, it is would be informative to compare them with the climatological fields. The major features in the JJA climatological MSLP pattern in the region, as shown by the shading in Fig. 5b, c, are: (a) the thermal low over the Asian continent, (b) the monsoon trough extending southeastward from southern China to the Philippine Sea, and (c) the ridge of the subtropical Pacific anticyclone over the subtropical western North Pacific. The positive MSLP anomaly observed in Fig. 5a indicates a generally weakening continental thermal low, except in central eastern China, and a weakening oceanic monsoon trough, while the negative MSLP anomaly reflects a weakening ridge over the East China Sea and Japan. These changes can be seen in Fig. 5b, c, by comparing the total MSLP fields in the two 15-year periods with the climatological MSLP. The comparison between the two figures indicates a southwestward extending subtropical ridge, and a development of weak trough over
Japan and the oceanic region to the east of Japan during the 1951-1965 period, relative to the circulation in 1936-1950 period. Such a change in the circulation configuration is similar to the anomalous circulation pattern that often leads to the opposite climate states in northern and southern China (e.g., Chang et al. 2000a, b; Hsu and Lin 2007). This can be understood as follows: a southwestward extending subtropical ridge reflects a more stable atmospheric condition and can therefore be responsible for less precipitation and higher temperature in the southern part of East Asia. On the contrary, the existence of a trough over northern China means less stable condition and could lead to more precipitation and lower temperature. These results have also been confirmed by an analysis based on the GMSLP, which yields essentially same results.

To understand the actual occurrence of abrupt temperature change, the climate regime shift analysis proposed by Rodionov (2004) was applied to the CRU temperature and the HadISST at every grid point in East Asia and the western North Pacific. Shading in Fig. 6 marks the location where positive RSI was found in JJA temperature during 1949-1953. The result indicates that the abrupt temperature change occurred in a wide area over the continental East Asia and the subtropical western North Pacific. The NRSI 
(a) MSLP difference

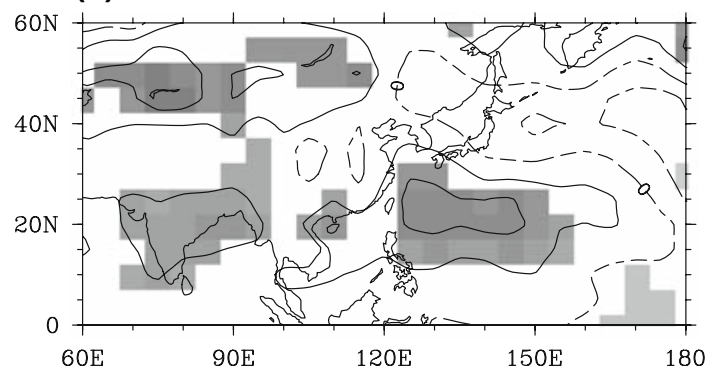

(b) $1936-1950$ mean

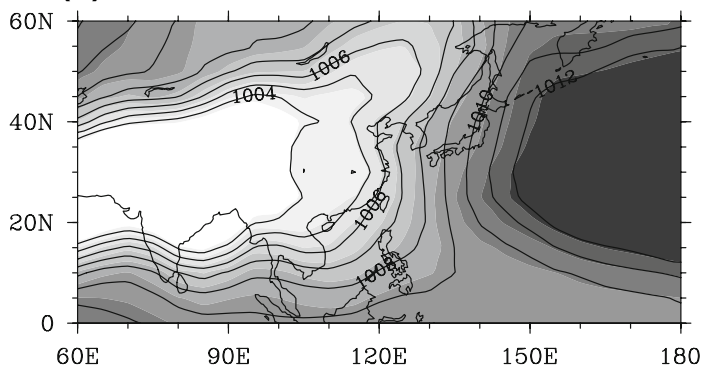

(c) 1951-1965 mean

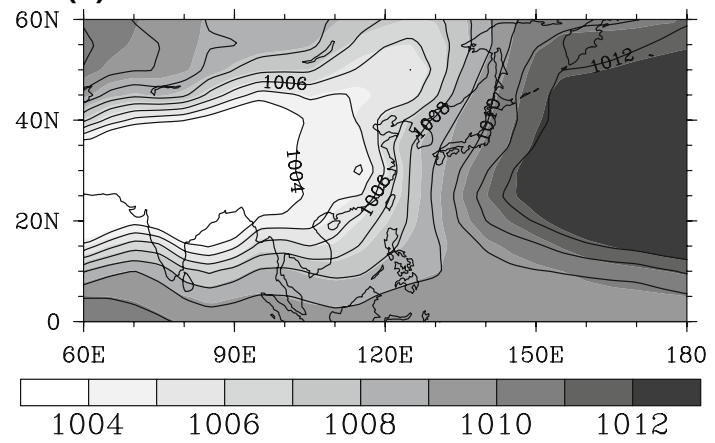

Fig. 5 MSLP plots for a the difference between 1951-1965 and 1935-1950, and the total field in b 1935-1950 and c 1951-1965. Shading in $\mathbf{b}$ and $\mathbf{c}$ represent the MSLP climatology. Contour intervals are 0.4 and $1 \mathrm{hPa}$ in $\mathbf{a}$ and $\mathbf{b}$, c, respectively. Solid and dashed lines in a denote positive and negative values, respectively. Values that are statistically significant at 0.1 level are shaded in a

summed over East Asia $\left(90^{\circ} \mathrm{E}-140^{\circ} \mathrm{E}, 20^{\circ} \mathrm{N}-50^{\circ} \mathrm{N}\right)$ for the temperature is shown in Fig. 7a. Three periods with the normalized NRSI greater than one Standard Deviation are found in the early 1930s, the early 1950s, and the mid1980s. The NRSI in the early 1950s is the largest among the three. The NRSI reached a high value in 1951 and remained almost the same for the next 4 years. This result is consistent with the identification of the 1951 temperature regime shift in Taiwan.

The same NRSI was computed by replacing the Rodionov method with the simple moving $t$-test method and the Mann-Whitney-Pittitt method. The results, shown in Fig. 7b, c, indicate large NRSIs in the early 1950s with peak around 1951 . While the early 1930s and mid-1980s

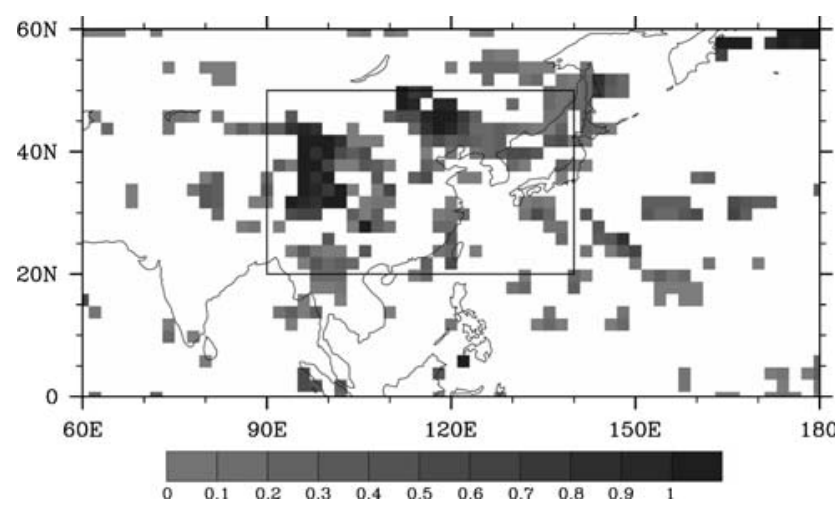

Fig. 6 RSI distribution for the temperature in 1949-1953. Locations with positive RSI are marked by shading. Darker shading denotes larger RSI

(a) SAT/SST

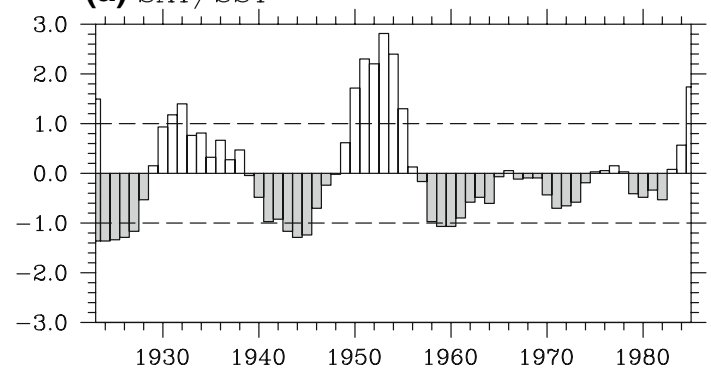

(b) Moving $t$-test method

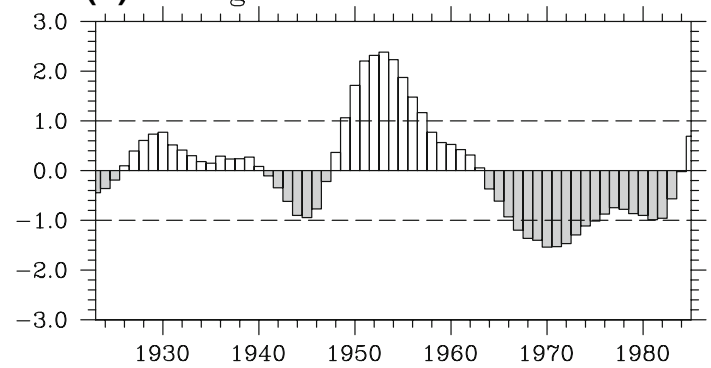

(c) Mann-Whitney-Pittitt method

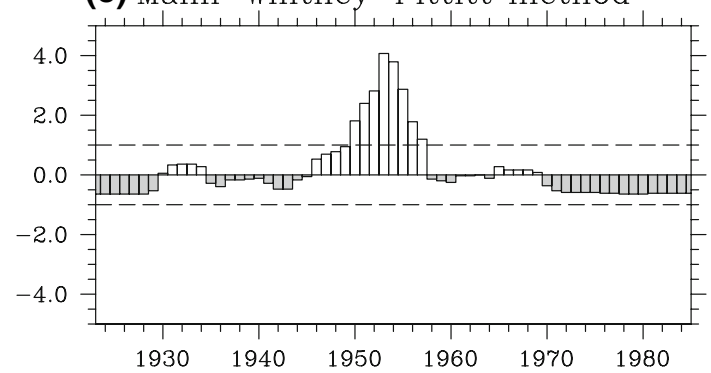

Fig. 7 NRSI time series for the CRU + HadISST in the $\left(90^{\circ} \mathrm{E}-\right.$ $140^{\circ} \mathrm{E}, 20^{\circ} \mathrm{N}-50^{\circ} \mathrm{N}$ ) region, based on a Rodionov, b simple moving $t$-test method, and c Mann-Whitney-Pittitt method. The NRSI at each year represents the total number of points with positive RSI over a 5 -year period centered at that year 
change did not survive this test, the early 1950s change remains evident and is strong enough to be insensitive to the different methodology. The Monte Carlo test indicates that a non-normalized NRSI of 55 points can be obtained at the 95th confidence level in the 1,000 randomly scrambled time series. The values of the NRSI in the early 1950s vary between 140 and 190, well exceeding the threshold 55 . This indicates the global significance of the observed change in the chosen domain.

The above results indicate that the abrupt temperature change in Taiwan, which occurred in the summers of the early 1950s, was under the influence of the large-scale temperature, precipitation, and circulation change in East Asia and the western North Pacific. The characteristics of this large-scale change pattern and its evolution are explored in the following sections to reveal the nature of this unique phenomenon, which has not been widely studied and reported.

\section{Temporal evolution from 1940s to $1950 \mathrm{~s}$}

This section examines the temporal evolution of the corresponding CRU temperature/SST and MSLP anomalies in the decadal time scale. Shown in Fig. 8 are a series of 9-year Gaussian mean CRU temperature/SST deviation from the long-term mean for every 3 years from 1942 to 1957. The temperature pattern in 1942 (Fig. 8a) exhibited the following characteristics: (a) positive anomaly in continental East Asia, the Indian Ocean, and the tropical and subtropical Pacific in both hemispheres, and (b) negative anomaly in the extratropical central North Pacific, Southeast Asia, and the Philippine Sea. The pattern remained basically the same by 1945 (Fig. 8b), except that the negative anomaly in the extratropical central North Pacific weakened significantly. By 1948 (Fig. 8c), the positive anomalies in the Pacific and the eastern Indian Ocean had dissipated significantly and were replaced by negative anomalies. In addition, the anomalies in the extratropical North Pacific and the Indian Ocean started changing signs. Polarity reversal occurred in most part of the oceanic region during the next few years. By 1951, strong positive and negative anomalies appeared in the extratropical North Pacific and the Indian Ocean, respectively (Fig. 8d). The positive anomaly in continental East Asia showed signs of weakening, while the negative anomaly in Southeast Asia and the Philippine Sea became more significant. In the next few years, the temperature over continental East Asia changed sign to negative, while the oceanic temperature pattern remained largely similar (Fig. 8d, e). Note that a positive temperature anomaly appeared in southeastern China, Taiwan, and the Philippines after 1951. This was about the time when the abrupt temperature increase occurred in Taiwan (Fig. 1).

Through the evolution, the negative temperature anomaly in the Philippine Sea strengthened, while the temperature anomaly in the extratropical western North Pacific became positive. Since the climatological SST maximum is located in the Philippine Sea and the SST decreases northward, the temperature anomaly change described above suggests a weakening of meridional SST gradient. Similar reduction in zonal temperature gradient also occurred in the extratropical East Asia. After 1950, the appearance of the negative temperature anomaly over continental East Asia and the positive temperature anomaly in the extratropical western North Pacific (Fig. 8e) indicates a reduced zonal temperature gradient and, therefore, a weakening land-sea contrast in the extratropical East Asia.

The evolution of the temperature anomaly was accompanied by a similar phase change in the MSLP anomaly (Fig. 9). In JJA 1942, the MSLP anomaly pattern exhibited the following characteristics: (1) positive in eastern China, Japan, the extratropical Pacific to the east of Japan, and the southern Indian Ocean, and (2) negative in the South China Sea, the western North Pacific between the equator and $30^{\circ} \mathrm{N}$, and the extratropical central Pacific near $160^{\circ} \mathrm{W}$ (Fig. 9a). Signs of these anomalies changed during the period from 1942 to 1951 (Fig. 9a, d). For example, the positive anomaly in Japan and the extratropical western North Pacific to the east of Japan changed sign from positive to weakly negative, while the negative anomaly in the western North Pacific between the equator and $30^{\circ} \mathrm{N}$ changed sign from negative to positive. During the same period, the MSLP anomaly in the Indian Ocean changed from positive to negative, while the MSLP anomaly in the eastern Pacific changed from negative to positive. The positive MSLP anomaly in the North Pacific and the negative anomaly in the Indian Ocean strengthened further in 1954. By 1957, a positive anomaly remained in the Philippine Sea, when positive anomaly developed in the extratropical Asian continent. One of the interesting features occurring in this period is the northwestward shift of the positive anomaly in the tropical western North Pacific. This shifting resulted in a stronger positive MSLP anomaly along the southeastern coast of China and in the Philippine Sea.

In summary, the change in temperature and MSLP was characterized by the phase reversal of a north-south dipole in the western North Pacific. This dipole tended to have a positive (negative) SST-negative (positive) MSLP anomaly relationship, e.g., by comparing Fig. 8a, e with Fig. 9a, e. The changing sign of this dipole in the early 1950s apparently resulted in the observed changes in temperature and precipitation discussed before. The 
(a) JJA 1942

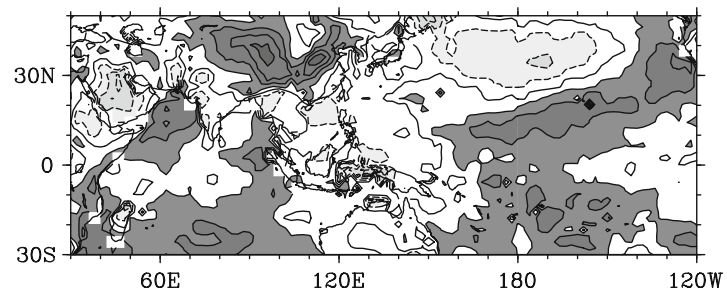

(c) JJA 1948

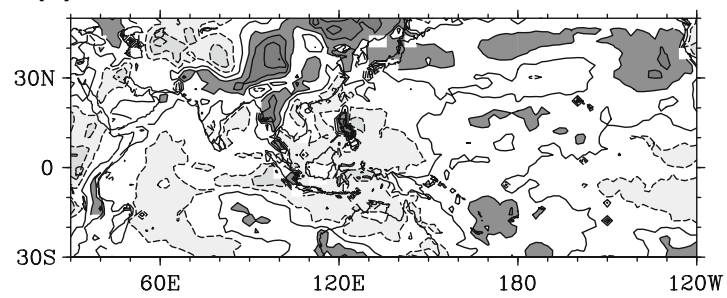

(e) JJA 1954

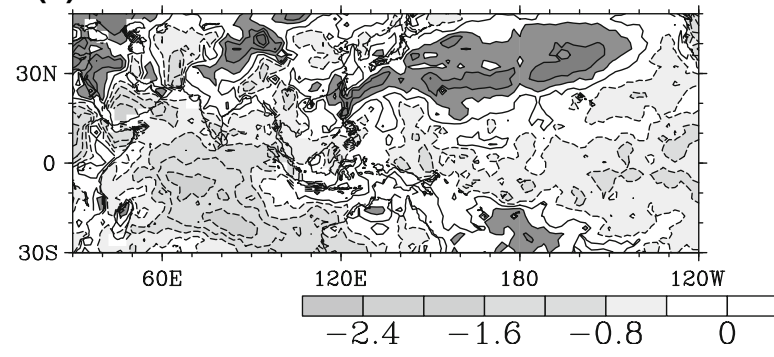

Fig. 8 Nine-year Gaussian running means of JJA temperature anomaly for a 1942, b 1945, c 1948, d 1951, e 1954, and f 1957. Values are normalized by the standard deviation. Contour interval is 0.4. Dark solid line denotes the zero line. Solid and dashed lines

evolution shown in Fig. 9 reflected the weakening continental thermal low, the monsoon trough, and the subtropical anticyclonic ridge from the late 1940s to the early 1950s. This phenomenon is accompanied by the cooling in China and warming in the subtropical western Pacific, indicating a reducing land-sea thermal contrast, as discussed above. These features all together suggest a weakening summer monsoon in East Asia, which was reported in previous studies, e.g., Hsu and Chen (2002).

The above changes can be further summarized in the Hovmüller diagrams shown in Fig. 10. The latitude-time plot shown in Fig. 10a presents the fluctuation of the 9-year Gaussian running-mean temperature averaged over $130^{\circ} \mathrm{E}-$ $160^{\circ} \mathrm{E}$ to illustrate the north-south flip-flop of the temperature in the western North Pacific. It clearly shows that the temperature anomaly south of $25^{\circ} \mathrm{N}$ had been flipping signs between positive and negative since 1920 and remained mostly negative between the mid-1940s and mid1980s. On the contrary, the temperature anomaly between $25^{\circ} \mathrm{N}$ and $40^{\circ} \mathrm{N}$ was weakly negative most of time between 1920 and 1940, turned positive around the mid-1940s, (b) JJA 1945

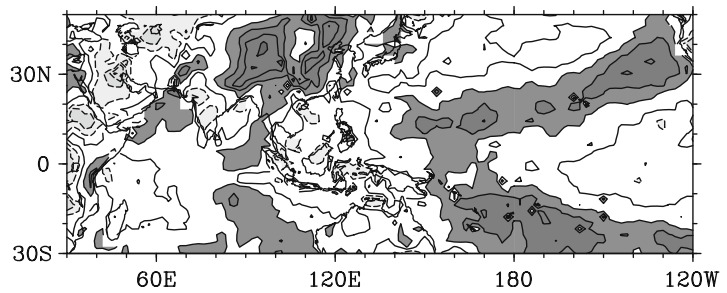

(d) JJA 1951

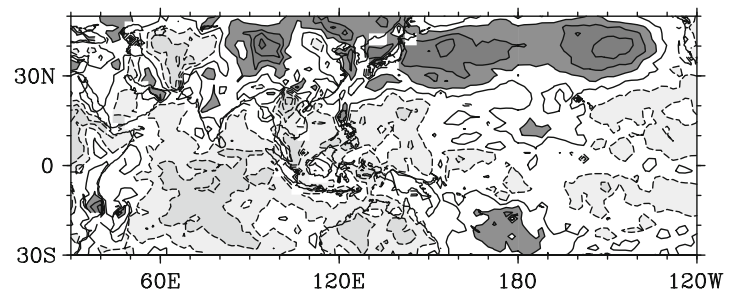

(f) JJA 1957

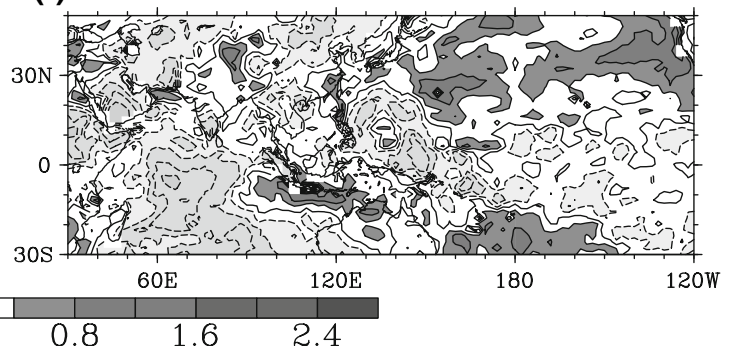

denote positive and negative values, respectively. Positive values larger and negative values smaller than one contour interval are shaded

reached the maximum amplitude in the early 1950s, and lasted to the mid-1970s. The changing sign in the mid1940s reflected the phase reversal of the PDO as reported in previous studies (e.g., Zhang et al. 1997; Mantua et al. 1997; Yasunaka and Hanawa 2002), and the weakening meridional temperature gradient as discussed above.

The Hovmüller diagram presenting the longitude-time plot of the 9-year Gaussian running-mean temperature averaged over $20^{\circ} \mathrm{N}-50^{\circ} \mathrm{N}$ (Fig. 10b) shows a similar phase shift around 1950. For example, the temperature anomaly between $90^{\circ} \mathrm{E}$ and $140^{\circ} \mathrm{E}$ (mostly over land) was mostly positive between 1930 and 1950 and turned negative after 1950. This negative anomaly, representing land cooling, continued strengthening until the mid-1970s and lasted to 1990 . In the oceanic region east of $140^{\circ} \mathrm{E}$, the temperature anomaly changed from negative anomaly to positive anomaly in the late 1940s and persisted for 30 years until the mid-1970s. This phase reversal of temperature anomaly in the extratropical North Pacific again reflected the fluctuation of the PDO, and also the weakening land-sea thermal contrast. 
(a) JJA 1942

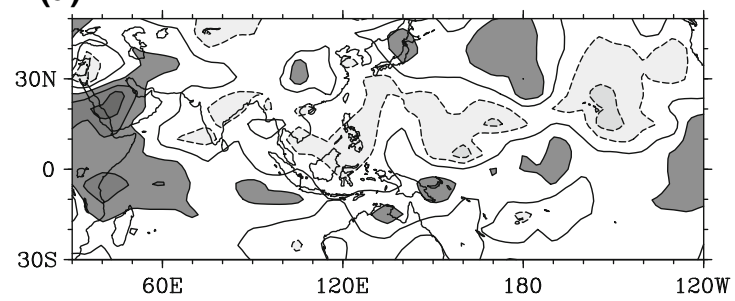

(c) JJA 1948

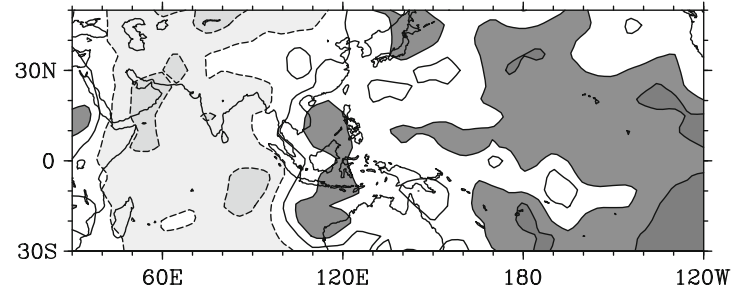

(e) JJA 1954

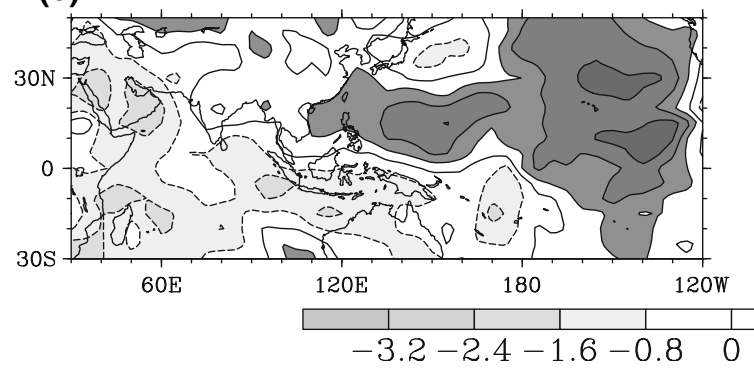

Fig. 9 Nine-year Gaussian running means of JJA MSLP anomaly for a 1942, b 1945, c 1948, d 1951, e 1954, and f 1957. Values are normalized by the standard deviation. Contour interval is 0.8 and zero (b) JJA 1945

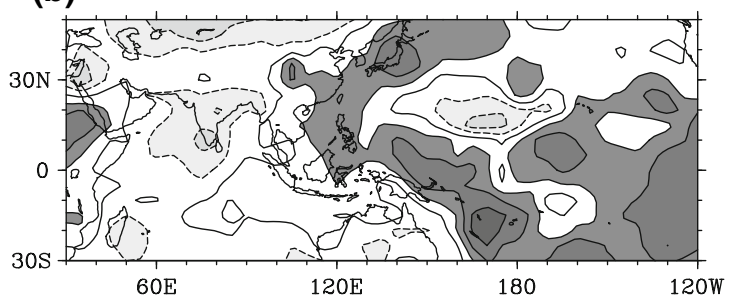

(d) JJA 1951

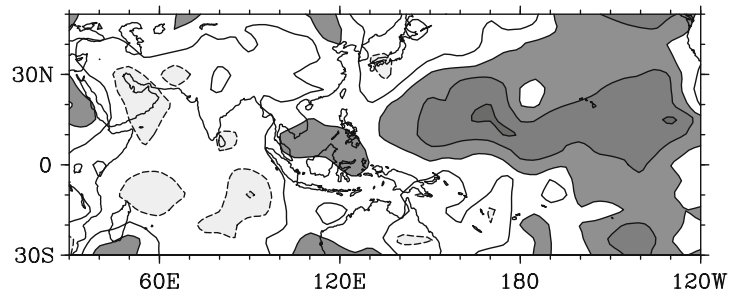

(f) JJA 1957

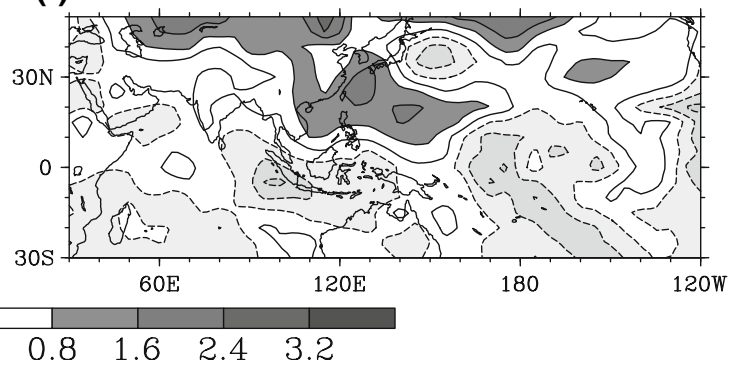

lines are marked by dark solid line. Solid and dashed lines denote positive and negative values, respectively. Positive values larger and negative values smaller than one contour interval are shaded

Interesting changes can also be seen in the Hovmüller diagram of MSLP. The MSLP averaged over $120^{\circ} \mathrm{E}-150^{\circ} \mathrm{E}$ shown in Fig. 10c revealed a gradual northward shift of the positive anomaly originating in the equator from 1940s to 1960s. This northward movement reached $20^{\circ} \mathrm{N}$ around 1950 , coinciding with the regime shift identified in this study, and continued moving northward to $40^{\circ} \mathrm{N}$ in the early 1960s. This positive anomaly remained mostly in the $10^{\circ} \mathrm{N}-30^{\circ} \mathrm{N}$ latitudinal band until the early $1970 \mathrm{~s}$. These features reflected the weakening of the monsoon trough and the southwestward penetration of the Pacific anticyclonic ridge as discussed above.

For the MSLP anomaly averaged over $30^{\circ} \mathrm{N}-50^{\circ} \mathrm{N}$ (Fig. 10d), sign changing also occurred around 1950. The anomaly was positive to the west of $130^{\circ} \mathrm{E}$ and negative to the east after 1950, but was in reversed phase before 1950 . Since climatologically there is a thermal low over the Asian continent and an anticyclone over the Pacific, the phase reversal of this east-west anomaly pair implies the weakening of the monsoon circulation in the extratropical East Asia after 1950.

\section{Conclusions and discussion}

A summer climate regime shift in temperature in Taiwan and East Asia during the early 1950s is identified in this study. This event was characterized by a cooling landwarming ocean dipole in East Asia and the western North Pacific. The cooling occurred in the extratropical East Asian land region, while the warming occurred in southeastern China, Taiwan, and the subtropical western North Pacific. The dipole marked the decreasing land-sea thermal contrast from the 1940s to the 1950s. The corresponding precipitation change, although weaker than temperature, exhibited decreasing tendency in southern China and Taiwan, and increasing tendency in northern China and Japan. This indicates a dipole exhibiting two contrasting climate conditions: warming and drying in the southern part of East Asian, and cooling and wetting in the northern part of East Asia.

This regime shift was found related to the evolution of the SST in the North Pacific. The SST anomaly in the extratropical central North Pacific changed sign in the mid- 


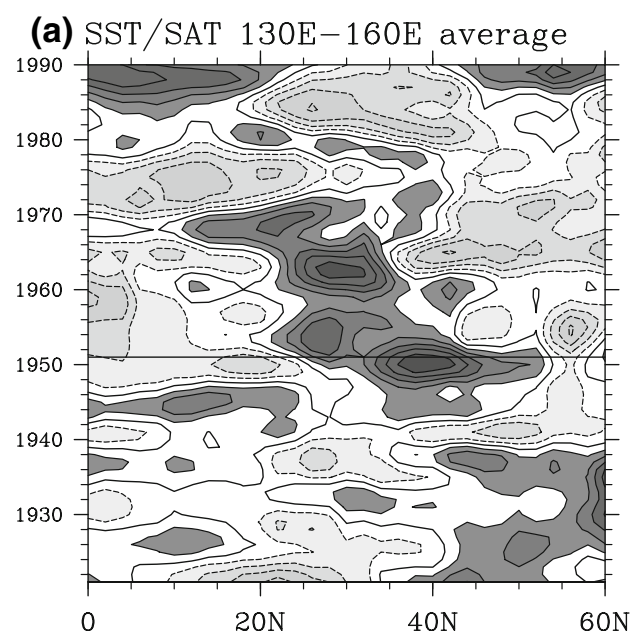

(c) SLP 120E-150E average

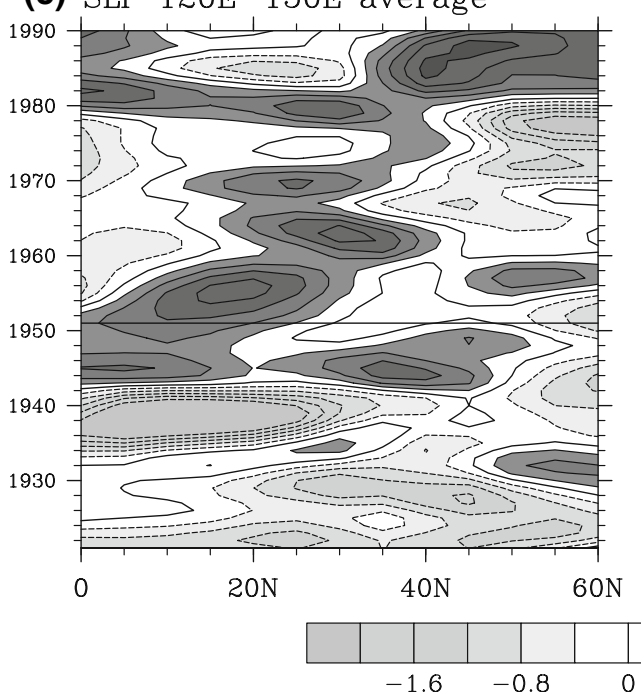

Fig. 10 Hovmüller diagrams for the JJA temperature anomaly averaged over a $130^{\circ} \mathrm{E}-160^{\circ} \mathrm{E}$ and $\mathbf{b} 20^{\circ} \mathrm{N}-50^{\circ} \mathrm{N}$, and the JJA MSLP anomaly averaged over c $120^{\circ} \mathrm{E}-150^{\circ} \mathrm{E}$ and $30^{\circ} \mathrm{N}-50^{\circ} \mathrm{N}$. Values are normalized by the standard deviation. Contour intervals are 0.2 for (b) SST/SAT 20N-50N average

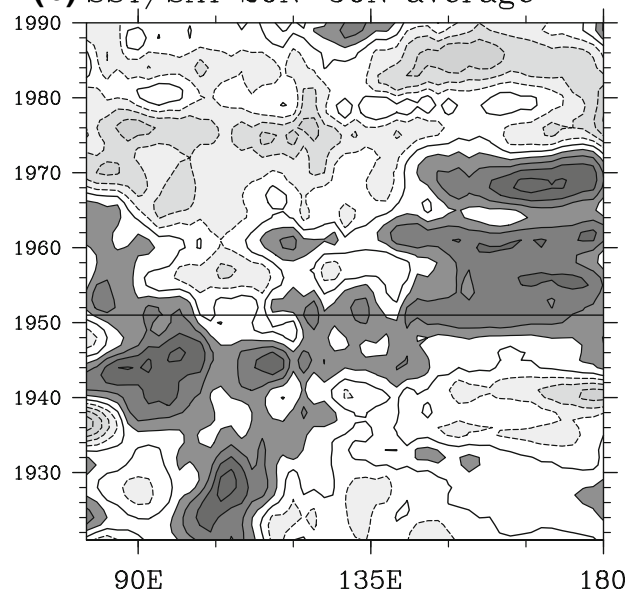

(d) SLP $30 \mathrm{~N}-50 \mathrm{~N}$ average

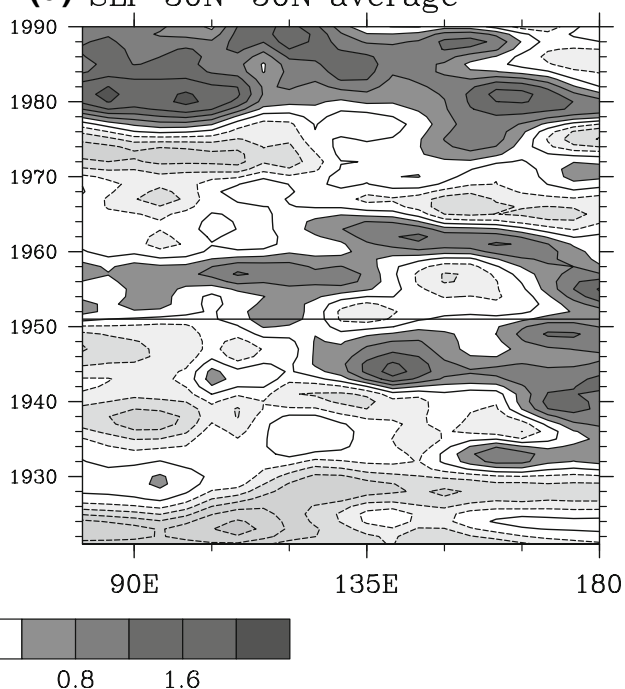

both temperature and MSLP. Positive values larger and negative values smaller than one contour interval are shaded. Zero lines are marked by dark solid lines. The horizontal line in each plot marks the year 1951

monsoon from the 1940s to 1950 s, which was consistent with the reducing land-sea thermal contrast inferred from the land cooling and ocean warming.

The southwestward-expanding subtropical ridge to Taiwan and the South China Sea is often associated with a more stable condition, higher temperature, and less precipitation in the region (e.g., Chang et al. 2000a, b). It also reflects a further northward penetration of the southwesterly prevailing in East Asia during the summer and often results in cooler and wetter summer climate in eastern China and Japan. Similar situation seemed to happen in the early 1950s and resulted in the climate regime shift.

The extratropical SST anomaly pattern shown above exhibits a great similarity to the SST anomaly distribution associated with the PDO, which affected the climate expanding subtropical ridge in the western North Pacific. These features suggested a weakening East Asian summer 


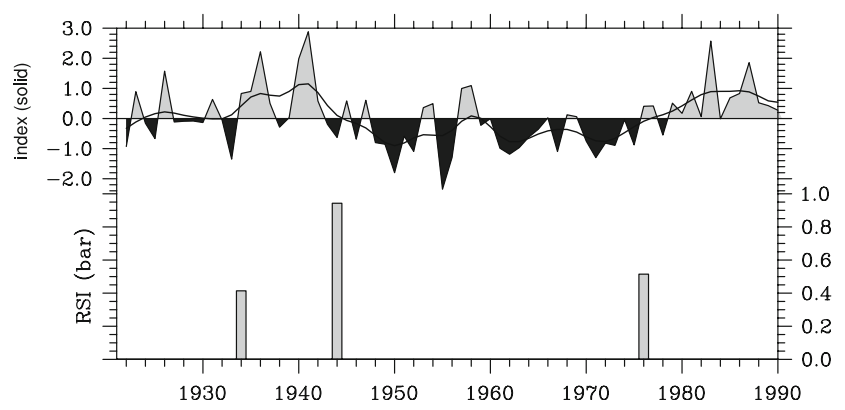

Fig. 11 Time series of the unfiltered and 9-year Gaussian runningmean JJA PDO index and corresponding RSI

variability in East Asia (e.g., Watanabe and Nitta 1999; Chan and Zhou 2005). As shown in Fig. 11, the JJA PDO has gone through two major phase changes since 1940, around 1944 and 1976 as indicated by the RSI. The result is consistent with previous studies (e.g., Zhang et al. 1997; Mantua et al. 1997; Hare and Mantua 2000; Yasunaka and Hanawa 2002). Considering the similarity of the observed SST anomaly pattern to the PDO and the delayed SST anomaly phase change in the Philippine Sea, the East Asian temperature regime shift in the early 1950 s may be influenced by the PDO, which exhibited a slow evolution in the North Pacific. However, there was a 6-7 years difference between the timings of the shift in East Asian temperature and the PDO. Whether a delayed impact of the PDO existed is an interesting issue for further studies.

During the boreal summer, the anomalous SST and convective activity in the tropical western North Pacific were found associated with the Pacific-Japan pattern (Nitta 1987), which is a north-south oriented wave-like pattern emanating from the Philippine Sea to the extratropical North Pacific. An atmospheric Rossby wave excited by the heating anomalies in the Philippine Sea was proposed to explain the existence of this wave-like structure (e.g., Kurihara and Tsuyuki 1987; Huang and Sun 1992). Recent studies further confirmed the impact of the tropical forcing on the anomalous circulation in East Asia, although mostly in the lower troposphere (Y. Kosaka and H. Nakamura 2006, submitted data; Hsu and Lin 2007). Although these results are mostly related to the interannual variability, similar impact may occur in East Asia and the western North Pacific in the interdecadal time scale, under the influence of the interdecadal SST variation. Applying this assumption, the SST cooling in the tropical western North Pacific might induce Rossby-wave like perturbation and result in the low-level anticyclonic anomaly in the southern part of East Asia and the western North Pacific (e.g., the Philippine Sea, Taiwan, and the South China Sea) and the low-level cyclonic circulation anomaly in the extratropical East Asia (e.g., eastern China, Japan, and the Pacific to the east of Japan). It would become warmer and drier in the former region, and cooler and wetter in the latter region under this situation. This conjecture seems consistent with the observed changes from the 1940s to 1950s.

One of the major difficulties for the study on the early 1950s climate regime shift is the limited observation, especially the upper-air observation. This is why this study was done based only on the surface data. Nothing about the condition in the free atmosphere is shown here. This deficiency certainly limits our understanding on this climate regime shift. Further studies are needed to improve this deficiency by using upper-air data (e.g., Met OfficeNorthern Hemisphere Geopotential Height data set) and with the aid of numerical studies. While many studies have been devoted to more recent climate regime shifts (especially the 1976/77 event), the early 1950s regime shift has been hardly studied and understood. This study takes the first step to explore the basic characteristics of this event and hopefully will attract more studies to untangle the mystery of this event.

Acknowledgments The authors thank anonymous reviewers for their valuable comments. This study is supported by the National Science Council in Taiwan under Grant NSC-95-2111-M-002-010MY3.

\section{References}

Allan R, Ansell T (2006) A new globally-complete monthly historical gridded mean sea level pressure data set (HadSLP2): 1850-2004. J Clim 19:5816-5842

An S-I, Wang B (2000) Interdecadal change of the structure of ENSO mode and its impact on the ENSO frequency. J Clim 13:20442055

Basnett TA, Parker DE (1997) Development of the global mean sea level pressure data set GMSLP2. Hadley Centre Climate Research Technical Note CRTN 79

Chan JCL, Zhou W (2005) PDO, ENSO and the early summer monsoon rainfall over South China. Geophys Res Lett 32. doi: 10.1029/2004GL022015

Chang C-P, Zhang Y, Li T (2000a) Interannual and interdecadal variations of the East Asian summer monsoon and tropical Pacific SSTs. Part I: role of the subtropical ridge. J Clim 13:4310-4325

Chang C-P, Zhang Y, Li T (2000b) Interannual and interdecadal variations of the East Asian summer monsoon and tropical Pacific SSTs. Part II: meridional structure of the monsoon. J Clim 13:4326-4340

Ducre-Robitaille JF, Vincent LA, Boulet G (2003) Comparison of techniques for detection of discontinuities in temperature series. Int J Climatol 23:1087-1101

Gong D, Ho C (2002) Shift in the summer rainfall over the Yangtze River valley in the late 1970s. Geophys Res Lett 29(10):1436. doi:10.1029/2001GL014523

Gullett DW, Vincent L, Sajecki PJF (1990) Testing homogeneity in temperature series at Canadian climate stations. CCC report 90-4, Climate Research Branch, Meteorological Service of Canada, ON, Canada

Hansen J, Ruedy R, Glascoe J, Sato M (1999) GISS analysis of surface temperature change. J Geophys Res 104:30997-31022 
Hare SR, Mantua NJ (2000) Empirical evidence for North Pacific regime shifts in 1977 and 1989. Prog Oceanogr 47:103-145

Ho C-H, Lee J-Y, Ahn M-H, Lee H-S (2003) A sudden change in summer rainfall characteristics in Korea during the late-1970s. Int J Climatol 23:117-128

Hsu H-H, Chen C-T (2002) Observed and projected climate change in Taiwan. Meteorol Atmos Phys 79:87-104

Hsu H-H, Lin S-M (2007) Asymmetry of the tri-pole rainfall pattern during East Asian summer. J Clim 20:4443-4458

Huang RH, Sun FY (1992) Impacts of the tropical western Pacific on the East Asia summer monsoon. J Meteorol Soc Japan 70:243-256

Hung C-W, Hsu H-H, Lu M-M (2004) Decadal oscillation of spring rain in northern Taiwan. Geophys Res Lett 31:L22206. doi: 10.1029/2004GL021344

Ju JH, Lu JM, Cao J, Ren J (2005) Possible impacts of the arctic oscillation on the interdecadal variation of summer monsoon rainfall in East Asia. Adv Atmos Sci 22(1):39-48

Kaplan A, Cane M, Kushnir Y, Clement A, Blumenthal M, Rajagopalan B (1998) Analyses of global sea surface temperature 1856-1991. J Geophys Res 103:18567-18589

Kiely G (1999) Climate change in Ireland from precipitation and streamflow observations. Adv Water Resour 23:141-151

Kurihara K, Tsuyuki T (1987) Development of the barotropic high around Japan and its association with Rossby wave-like propagations over the North Pacific: analysis of August 1984. J Meteorol Soc Jpn 65:237-246

Mantua NJ, Hare SR, Zhang Y, Wallace JM, Francis RC (1997) A Pacific interdecadal climate oscillation with impacts on Salmon production. Bull Am Meteorol Soc 78:1069-1079

Miller AJ, Cayan DR, Barnett TP, Graham NE, Oberhuber JM (1994) The 1976-1977 climate shift of the Pacific Ocean. Oceanography 7:21-26

Mitchell TD, Carter TR, Jones PD, Hulme M, New M (2004) A comprehensive set of high-resolution grids of monthly climate for Europe and the globe: the observed record (1901-2000) and 16 scenarios (2001-2100). Tyndall Centre Working Paper 55, Norwich, UK, p 30

Nitta T (1987) Convective activities in the tropical western Pacific and their impact on the Northern Hemisphere summer circulation. J Meteorol Soc Jpn 65:373-390

Nitta T, Yamada S (1989) Recent warming of tropical sea surface temperature and its relationship to the Northern Hemisphere circulation. J Meteorol Soc Jpn 67:375-383

Pittitt AN (1979) A nonparametric approach to the change point problem. Appl Stat 28:126-135
Rayner NA, Parker DE, Horton EB, Folland CK, Alexander LV, Rowell DP, Kent EC, Kaplan A (2003) Global analyses of sea surface temperature, sea ice, and night marine air temperature since the late nineteenth century. J Geophys Res 108:D14, 4407. doi:10.1029/2002JD002670

Rodionov SN (2004) A sequential algorithm for testing climate regime shifts. Geophys Res Lett 31:L09204. doi:10.1029/ 2004GL019448

Rodionov SN, Overland JE (2005) Application of a sequential regime shift detection method to the Bering Sea ecosystem. ICES J Mar Sci 62:328-332

Seager R, Kushnir Y, Naik NH, Cane MA, Miller J (2001) Winddriven shifts in the latitude of the Kuroshio-Oyashio extension and generation of SST anomalies on decadal timescales. J Clim 82:4249-4265

Smith TM, Peterson TC, Lawrimore JH, Reynolds RW (2005) New surface temperature analyses for climate monitoring. Geophys Res Lett 32:L14712. doi:10.1029/2005GL023402

Tachibana Y, Honda M, Takeuchi K (1996) The abrupt decrease of the sea ice over the southern part of the Sea of Okhotsk in 1989 and its relation to the recent weakening of the Aleutian Low. J Meteorol Soc Jpn 74:579-584

Tanimoto Y, Iwasaka N, Hanawa K, Toba Y (1993) Characteristic variations of sea surface temperature with multiple time scales in the North Pacific. J Clim 6:1153-1160

Trenberth KE (1990) Recent observed interdecadal climate changes in the Northern Hemisphere. Bull Am Meteorol Soc 71:988-993

Trenberth KE, Hurrell JW (1994) Decadal atmosphere-ocean variations in the Pacific. Clim Dyn 9:303-319

Watanabe M, Nitta T (1999) Decadal changes in the atmospheric circulation and associated surface climate variations in the Northern Hemsphere winter. J Clim 12:494-510

Weng H, Lau K-M, Xue Y (1999) Multi-scale summer rainfall variability over China and its long-term link to global sea surface temperature variability. J Meteorol Soc Jpn 77:845-857

Wu R, Wang B (2002) A contrast of the East Asian summer monsoon and ENSO relationship between 1962-1977 and 1978-1993. J Clim 15:3266-3279

Yasunaka S, Hanawa K (2002) Regime shifts found in the Northern Hemisphere SST field. J Meteorol Soc Jpn 80:119-135

Yonetani T (1992) Discontinuous climate changes in Japan after 1900. J Meteorol Soc Jpn 70:1125-1136

Zhang Y, Wallace JM, Battisti DS (1997) ENSO-like interdecadal variability: 1900-1993. J Clim 10:1004-1020 